\title{
DIFERENTES CONTEXTOS TRANSACIONAIS E SUAS LIGAÇÕES COM O EMPREENDEDORISMO, A EFETUAÇÃO E A BRICOLAGEM
}

Reed Nelson ${ }^{1}$

Edmilson Lima ${ }^{2}$

\footnotetext{
${ }^{1}$ FACCAMP

${ }^{2}$ Programa de Pós-Graudação em Administração / Universidade Nove de Julho
} 


\title{
DIFERENTES CONTEXTOS TRANSACIONAIS E SUAS LIGAÇÕES COM O EMPREENDEDORISMO, A EFETUAÇÃO E A BRICOLAGEM
}

\begin{abstract}
Resumo: A racionalidade formal, que sustenta a corrente da economia neoclássica, negligencia muitos e importantes traços do contexto transacional do empreendedorismo, principalmente os socioculturais. Até mesmo as correntes recentes da efetuação e da bricolagem em empreendedorismo, que emergiram em parte para compensar limitações da racionalidade formal, não detalham aspectos de tal contexto. Buscando contribuir para a superação dessa limitação, este trabalho explora o contexto transacional do bazar (Geertz, 1979) e o contrastada a outros: mercado clássico, bazar pós-moderno, hierarquia e organização em rede. Assim, explicitamos importantes influenciadores contextuais do empreendedorismo, em especial para efetuadores (Sarasvathy, 2001) e bricolores (Baker e Nelson, 2005). Entre as conclusões elaboradas, apontamos desafios que podem marcar a vida de empreendedores, que tendem a atuar na interseção de diferentes contextos transacionais.
\end{abstract}

Palavras-chave: empreendedorismo, contextos transacionais, bazar, efetuação, bricolagem.

\section{Introdução}

Os múltiplos estudos sobre a efetuação e a bricolagem, iniciados respectivamente por Sarasvathy (2001) e Baker e Nelson (2005), ilustram a pluralidade do empreendedorismo para além da descrição racional formal. Com base na racionalidade formal, a corrente da economia clássica no empreendedorismo apresenta esse fenômeno como realizado segundo as etapas de obtenção de informações abundantes e facilmente acessíveis, análise e planejamento ótimos feitos por pessoas isentas e desinteressadas, fixação racional de objetivos e, enfim, sua realização no mercado. A abordagem desconsidera o contexto sociocultural, em associação ou não com o conceito de mercado. Ademais, ela pauta-se pela consideração de ações atomizadas dos atores econômicos, enquanto já se sabe que tais ações são socialmente imbricadas (Durkheim, 1977; Granovetter, 1985; Weber, 1991).

Uma ilustração das questões suscitadas por essas limitações vem de diferentes abordagens da racionalidade e da ação empreendedoras metaforicamente consideradas na comparação de alguns esportes, um esporte no qual a informação não é problemática com outro em que a aquisição e a interpretação de informações é difícil, mas central. $O$ entendimento de que oportunidades empreendedoras e recursos seguem a racionalidade clássica lembra uma corrida de rua. Nesse esporte, como nos mercados clássicos, a informação está prontamente disponível e não é problemática, de modo que oportunidades e recursos são facilmente localizáveis e analisáveis. Na corrida, é pública e obtém-se facilmente a informação sobre quando e onde a competição vai começar, onde é a linha de chegada e qual é o trajeto para se chegar a ela. Assim, a única real questão é sobre quem vai correr mais rapidamente. Se pensarmos no empreendedorismo como um esporte diferente, como a caça ou a pesca, o entendimento muda completamente.

Os organizadores de uma competição de caça ou pesca podem também definir um momento e um lugar para o evento, mas quase todas as outras informações relevantes são problemáticas. $\mathrm{O}$
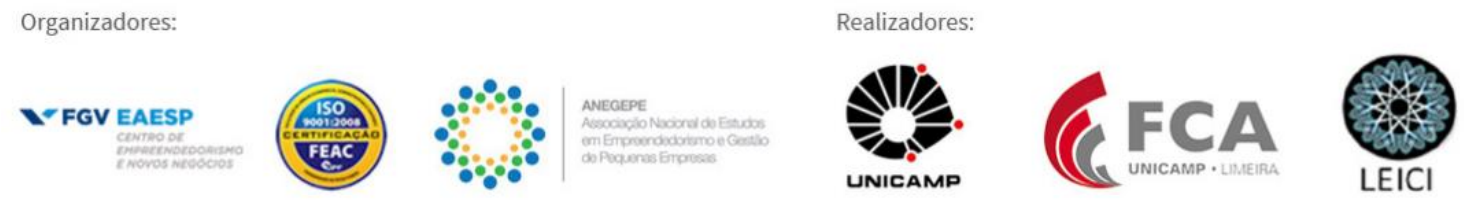
êxito nesses esportes depende da obtenção e da transmissão de informações não facilmente acessíveis. Onde está a presa? Como eu a encontro? Como eu deveria abordá-la? Qual isca uso? Como e quando devo agir? Qual é o melhor equipamento? Por muitos anos, o campo do empreendedorismo foi visto mais como uma corrida de rua. No começo, muitas pesquisas foram feitas para caracterizar atributos pessoais de quem tenderia a vencê-la. Não foi surpresa que velocidade, agressividade e enfrentamento de risco foram identificados como traços dos empreendedores. Com o passar do tempo, contudo, a pesquisa tornou-se muito mais detalhada e focada no comportamento e no mundo socialmente construído do empreendedor, tanto que teorias recentes, como a da efetuação (Sarasvathy, 2001), focam não na "natureza do esporte" - ou seja, nas condições e circunstâncias da ação empreendedora - mas mais nos componentes do mundo mais imediato dos empreendedores - sua rede social, o que sabem, sua identidade e o maior nível de risco que aceitam enfrentar numa iniciativa.

Esse foco mais recente constitui um importante avanço devido à natureza altamente idiossincrática dos empreendedores e da ação empreendedora. Contudo, é o processo, a "natureza da competição", que tem sido negligenciado. Isso quer dizer que pouca atenção tem sido dada ao contexto das ações e transações empreendedoras. Desse modo, o campo está agora olhando cuidadosamente para os competidores e dedicando menos atenção à descoberta da natureza do esporte do empreendedor. Neste artigo, buscamos chamar atenção para esse olhar e descrever alguns dos principais contextos transacionais nos quais os empreendedores tendem a operar.

O contexto sociocultural não é direta e explicitamente abordado nas correntes teóricas recentes do empreendedorismo, como as da efetuação e da bricolagem. Ainda que ambas sejam um complemento relevante para a corrente da racionalidade formal, tornando mais realista o entendimento do empreendedorismo, atêm-se aos aspectos sociais mais imediatos de relações atomísticas dos empreendedores (ex.: colaboração com membros de sua rede de relação e de sua organização, implicação de stakeholders, relações com clientes). Adicionalmente, o próprio campo mais geral do empreendedorismo precisa de uma abordagem socioculturalmente contextualizada. A importância e a necessidade da contextualização no estudo do empreendedorismo já foram caracterizadas (ex.: Lalèyê et al., 1996; Watson, 2013; Welter, 2011; Welter e Gartner, 2016). Ademais, o contexto sociocultural mostra-se incontornável, pois o empreendedorismo é um fenômeno de relações sociais (Davidson, 2008), condição confirmada principalmente por estudos sociológicos olhando-o para além de questões psicológicas e econômicas (Ruef and Lounsbury, 2007).

Encontramos na descrição do bazar marroquino de Sefrou (Geertz, 1979) contribuições relevantes para a superação da limitação das correntes da racionalidade formal, da efetuação e da bricolagem, as quais não consideram o contexto sociocultural do empreendedorismo. No entanto, outros tratamentos conceituais são necessários antes de abordarmos o bazar.

\section{Diferenças e ligações: racionalidade formal, bricolagem e efetuação}

Há várias décadas, as sociedades já são advertidas quanto aos exageros no uso da racionalidade formal, que levaram a graves fricções entre a eficiência econômica e a real condição humana, chegando até mesmo à substituição da sociedade tradicional pela "gaiola de ferro da racionalidade formal" (Weber, 1968, 1947). A corrente da economia clássica, ainda central no empreendedorismo, guia-se pela racionalidade formal. Esta pressupõe que os tomadores de decisão podem facilmente obter todas as informações de que precisam e tratá-las otimizando as decisões, que as pessoas que as fornecem e buscam são neutras e que a escolha e o uso de objetivos e meios

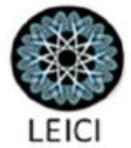


para realizá-los resultam de um processo plenamente técnico e isento de influências culturais e políticas.

Contudo, diferentes abordagens mais recentes em empreendedorismo complementam essa perspectiva ao mesmo tempo em que a contrariam, dando atenção particular às práticas e ações emergentes dos empreendedores, assim como ao mundo subjetivo deles. Como lembram Lima e Nelson (2016), entre essas abordagens, duas estão em evidência ultimamente: as da efetuação (Sarasvathy, 2001) e da bricolagem (Baker e Nelson, 2005). A efetuação constitui o contrário da "causação", ou seja, ao invés da sequência de prever os efeitos de uma ação, tomar decisões plenamente racionais, estabelecer objetivos, obter recursos para realizá-los e, enfim, passar à ação escolhida que realiza tais objetivos, Age-se segundo a consideração dos meios à disposição e das respostas obtidas para as questões de base da efetuação. As questões são: "Quem sou eu?", "O que eu sei?", “Quem eu conheço?” e “Quais perdas são aceitáveis para mim?”. Explorando seus meios e as respostas a essas perguntas, o efetuador estabelece objetivos factíveis e age com pouco risco.

Um exemplo imaginário parece útil para se diferenciar a racionalidade formal da efetuação. Já tendo trabalhado por muito tempo na locação de material esportivo em uma praia catarinense movimentada onde vive e conhecendo a demanda por pranchas de surfe de aluguel durante os fins de semana de verão nessa mesma praia, uma empreendedora sabe que ela mesma pode alugar antecipadamente de uma empresa numa praia menos movimentada, por três dias, um conjunto de 10 pranchas e as sublocar na praia em que vive. Para os três dias do fim de semana, ela sabe, após ter avaliado outras possibilidades de investimento que considerou menos atraentes, que ela pagará um total de $\mathrm{R} \$ 300,00$ de locação e sublocará as pranchas por hora obtendo uma receita líquida total entre R \$ 1.200,00 e 1.500,00. Ela toma então a oportunidade percebida como objetivo e a explora por vários fins de semana, sabendo que ganhará de $\mathrm{R} \$ 900,00$ a 1.200,00 por fim de semana após ter pagado um colaborador temporário, o transporte das pranchas e outros custos, além de ter recebido algumas comissões de professores de surfe para quem indica novos clientes. Isso exemplifica a racionalidade formal na prática, diferentemente dos exemplos seguintes.

Lima e Nelson (2016) oferecem dois exemplos respectivamente referentes à efetuação e à bricolagem. Segundo eles, um cálculo tão direto quanto na sublocação de pranchas poderia não ser a melhor opção, por exemplo, para a produção de filme de uma empreendedora com 20 anos de experiência na produção independente de documentários políticos, mas estando agora quase sem dinheiro. Pensando nas possibilidades para um novo projeto, ela leva em conta o favor que um ator sino-americano bem conhecido lhe deve, que ele é sensível à causa do aquecimento global, que ela dispõe de 250.000 milhas de voo em um programa de fidelidade para viagens e que ainda tem dois meses de locação de câmeras de vídeo ao seu dispor. Aproveitando esses ativos, decide produzir um filme sobre emissões de gás carbônico na China. Sua decisão e as ações correlatas são bem mais complexas do que as do exemplo precedente, mas podem ser um investimento mais rentável. A empreendedora em questão se faz as quatro perguntas de base da efetuação mencionadas acima (“Quem sou eu?"...) e as respostas orientam suas ações empreendedoras sem muito risco.

O conceito de bricolagem (Archer, Baker e Mauer, 2009; Lévi-Strauss, 1962) tem uma história mais longa e mais diversificada que o de efetuação (Sarasvathy, 2001). Seu significado mais comum é o de se virar com os meios à disposição (Lévi-Strauss, 1962). Em empreendedorismo, ele é mais frequentemente entendido como "se virar aplicando combinações de recursos à disposição a problemas e oportunidades novos" (p. 333, tradução nossa). A adaptação do exemplo de produção de filme da efetuação para a bricolagem poderia ocorrer nos seguintes termos (Lima e Nelson, 2016). A produtora não começaria por considerar as quatro questões mencionadas, mas manter-se-ia

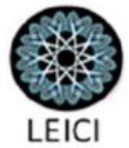


concentrada nas combinações e nos testes possíveis de seus recursos facilmente utilizáveis para realizar os objetivos. Desse modo, assim que ela toma conhecimento que um de seus colaboradores frequentes dispõe de um financiamento a fundo perdido para uma campanha contra o aquecimento global, seu reflexo é de explorar seus recursos possivelmente da seguinte maneira: (1) procurar em sua videoteca e usar trechos de vídeos úteis; (2) reativar um website pertinente que ela possui; (3) persuadir um amigo a ajudá-la a aperfeiçoar conteúdos de um PowerPoint e os integrar ao website e a passagens de um vídeo educativo; (4) usar informações vindas de documentos governamentais explorando a lei de acesso à informação. Ao invés de se impor um limite de custos e de risco a respeitar, ela se concentraria em problemas cuja solução poderia vir de uma recombinação de recursos a sua disposição. Portanto, seu pensamento e suas ações seriam menos determinados por "quem ela é" ou por "o que ela pode fazer" e mais pela natureza do problema a resolver e pelos recursos a sua disposição. Ela também se perguntaria sobre quem ela conhece. Contudo, a partir daí, buscaria a colaboração de pessoas com disponibilidade mais imediata em sua rede.

Podemos ver nos três exemplos acima que o foco está centrado nas ações e atributos dos empreendedores - seus processos de busca, suas transações sociais, sua base de conhecimento e assim por diante. Há uma aceitação implícita, e às vezes explícita, na literatura correlata dos exemplos de que as ações vão variar de acordo com o contexto, mas pouco se fez e se faz nela para se explicar possíveis contextos e seus efeitos. Assim, por exemplo, Sarasvathy (2001) observa que os empreendedores podem passar da efetuação à causação à medida que seu negócio ganha maturidade. Contudo, enquanto pesquisadores do empreendedorismo já estão agora confortáveis com a ideia de que os empreendedores não são classicamente racionais, parecem assumir que o contexto no qual estes atuam equivale ao mercado neoclássico no qual as informações são facilmente acessíveis, transitam rapidamente e não se distorcem, assim como fornecedores e clientes são numerosos e não influenciados por tradições, obrigações recíprocas etc.

Parece que este não é sempre o caso. De fato, acreditando-se no que dizem sociólogos como Granovetter (1985), pode-se argumentar que isso raramente se aplica. Buscando provocar reflexões sobre diferentes contextos transacionais e como influenciam a ação empreendedora, vamos agora discutir contextos nos quais tal ação tende a ocorrer: o mercado neoclássico, o bazar tradicional, o bazar pós-moderno, a hierarquia e a organização em rede. Poderemos constatar o caráter promissor do bazar e de sua confrontação a outros contextos (ver também o quadro 1 no anexo).

\section{O Mercado Neoclássico}

A constituição do mercado neoclássico inclui mais de um vendedor e ao menos um comprador, todos não impedidos e não influenciados por qualquer questão não econômica e compartilhando informações sem restrição. Teoricamente, esse arranjo leva rapidamente a um preço estável e transparente que é vasta e facilmente conhecido em todo o mercado. Para Cournot (1838), os economistas compreendem o 'mercado' não como um local em particular onde coisas são compradas e vendidas, mas como o todo de uma região na qual compradores e vendedores encontram-se em tal liberdade de interação um com o outro que os preços dos mesmos bens tendem fácil e rapidamente à igualdade. Essa definição favorece produtos que são tangíveis e similares entre si, como óleo cru, tomates ou água mineral - exemplos do próprio Cournot (1838) -, havendo um valor corrente para bens e serviços até mesmo quando a qualidade, a quantidade ou a entrega variam e as dinâmicas de mercado são aproximadas em muitas situações, como conserto de carros, venda de imóveis, pagamento de salários a trabalhadores do fast food ou estabelecimento de custos da construção civil.

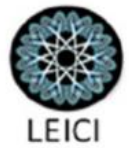


Nas situações de forte dinâmica de mercado, os participantes mais rápidos a dar escala a suas atividades tendem a dominar porque podem negociar descontos em suas compras e gerar melhorias de eficiência administrativa que lhes asseguram uma vantagem concorrencial. Dito isso, a competição frequentemente não é tão prejudicial a ponto de impedir que pequenos concorrentes vivam relativamente bem. Pequenos laboratórios que fazem exames veterinários com imagens para gatos, pequenas empresas que alugam impressoras laser ou pequenos centros de reciclagem que compram latas de alumínio ou pedaços de cobre comumente oferecem uma vida razoável para seus donos e às vezes também para seus empregados. Nesses casos, contudo, a ênfase em racionalidades alternativas, como a efetuação e a bricolagem, não tende a se mostrar útil para o empreendedor. Se você está comprando latas de alumínio para viver ou vendendo doces no semáforo, não é particularmente útil se perguntar "quem você é", "o que você sabe" etc. Nem as questões que se põem ao bricolor sobre recursos disponíveis, habilidades de parceiros etc. serão centrais. Ao contrário, os métodos racionais de otimização, eficiência e execução tendem a ser os mais úteis.

\section{$4 O$ bazar tradicional}

O conceito de bazar usado neste trabalho vem do reconhecido estudo etnográfico de Geertz (1978, 1979), que ele classifica como análise cultural. No estudo, o bazar é o tradicional mercado público de uma cidade marroquina de menos de 30.000 habitantes, Sefrou, no qual cerca de 300 fabriquetas e 600 lojas produzem e vendem produtos variados. Geertz $(1978,1979)$ vê no bazar não só um âmbito para se comprar barato e se vender caro, eventualmente enganando-se o próximo, mas também uma fluida comunidade cuja vida é moldada sociocultural e economicamente. Uma vasta trama de relações sociais permite a seus participantes negociar, de modo aparentemente caótico, bens, serviços, recursos financeiros, valores, símbolos e/ou informações, configurando uma economia de bazar (Geertz, 1978, 1979).

Nota-se, com essas características, que a abordagem da economia de bazar difere claramente da teoria neoclássica de mercado por evidenciar que o mercado não é fechado em si mesmo com participantes que obedecem apenas a motivações e pressões endógenas (Cefaï, 2003). Além disso, ela descreve e ilustra como os aspectos socioculturais endógenos e exógenos ao bazar influenciam as atividades de negócio dos participantes deste. É nesse sentido que o conceito de bazar faz-se útil para contrabalançar a negligência dos aspectos socioculturais nas correntes racionais formais e a modesta consideração desses aspectos nas correntes da efetuação e da bricolagem.

Inversamente ao conceito de mercado, o conceito de bazar não é de conhecimento corrente para os leitores em geral, de modo que se faz necessário descrevê-lo aqui com mais detalhe.

\subsection{Amplitude e Confiança no Bazar Tradicional}

Enquanto no mercado os preços evoluem rapidamente para o equilíbrio, os preços do bazar são construídos usando-se um processo de negociação semitransparente e complexo, sendo o desenvolvimento da proximidade social e a manutenção de parcerias de negócio algumas das mais difíceis e importantes atividades dos participantes do bazar.

As primeiras definições de mercado referem-se a locais físicos dedicados à negociação. Por isso, a definição clássica de Cournot (1838) começou esclarecendo que, para o economista, um mercado não é um local físico, mas muito mais um arranjo ou contexto no qual as pessoas e as informações sobre preço transitam de modo rápido e convergente. Por outro lado, o bazar ainda reteve sua identidade como um lugar concreto de transações, mesmo que existam também ao menos duas novas interpretações de bazar. As duas são concepções metafóricas do bazar, uma para descrever

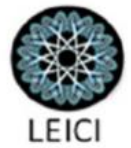


trocas de conhecimento no trabalho baseado no conhecimento (Hargadon, 2001) e outra para descrever o desenvolvimento de softwares livres por especialistas on line (Raymond, 1999).

Além de detalhes sobre a origem e a diferenciação do bazar tradicional em comparação ao mercado tradicional local (ver anexo on line), nota-se que uma diferenciação do bazar é que a busca por informação é a experiência central de seus participantes, até porque descobrir as opções disponíveis de bens, serviços e preços é o primeiro problema que enfrentam (Geertz, 1978, 1979). Omissão, manipulação, oferta e busca de informações levam ao desenvolvimento de redes de relação peculiares no bazar, estabelecendo, nessas redes, campos de disputa e de colaboração, hierarquias, identidades e a aplicação de variadas estratégias retóricas na busca de bons negócios e particularmente na barganha (Mello, 2005). Acesso à informação dificultada é, portanto, condição de prosperidade no bazar.

Turistas, por exemplo, fazem um contraponto em relação àqueles que conhecem bem o bazar. São dos que têm menor acesso a informações nesse contexto e mais problemas por falta delas. Tendem a pagar mais caro e a adquirir produtos de baixa qualidade por não poderem acessá-las e por não terem laços sociais com integrantes do bazar. Clientes locais têm custos de transação, assim como turistas, mas têm o benefício de os vendedores quererem que voltem, o que lhes garante certa proximidade social e lhes dá condições vantajosas de compra (Williamson, 1975). Ademais, podem mais facilmente levantar preços e condições com vários ofertantes, mesmo tendendo a voltar enfim a fazer negócio com ofertantes habituais, com quem barganham intensamente e estabelecem laços relativamente duradouros de conveniência. A relação dá certa segurança ao comprador de que não será enganado e de que está comprando em melhores condições do que um desconhecido. Por outro lado, dá ao ofertante a expectativa de que o cliente voltará. Nessas dinâmicas sintetizadas por McMillan (2003), a relação minimiza custos de transação e de obtenção de informação para ambos os lados e lhes oferece melhores chances de bons negócios. Intermediários, mediante algum ganho que onera uma ou ambas as partes, podem também levar ofertantes e clientes desconectados a rapidamente obter vantagens similares às de uma relação já estabelecida. Uma vantagem central que oferecem é baixar o custo de procura para as partes, o que torna o mercado mais eficiente, assim como fazem outros conectores, como o comércio eletrônico (McMillan, 2003).

A forma apenas econômica do bazar é recorrente em muitos países, mas sua dimensão cultural é única para cada localidade. Para Sefrou, Geertz (1979) descreve a diversidade étnica e religiosa como determinante da vida no bazar, particularmente quanto à imbricação num mundo árabe de diferenças étnicas, à conexão com instituições islâmicas e ao papel ativo da comunidade judaica.

\section{O Bazar Pós-Moderno}

Usos mais recentes do conceito de bazar aplicam-no frequentemente como uma metáfora a situações diferentes das transações de compra e venda de um bazar tradicional. Esses usos exploram as noções centrais do conceito em maior ou menos grau, como dinamismo, cultura compartilhada, diversidade, caos aparente e transações entre partes aparentemente pouco conectadas num mar de incertezas e carência de informação. Hargadon (2001) usa a metáfora abordando o trabalho baseado em trocas de conhecimento. Para ele, pessoas em organizações participam conjuntamente na geração de soluções e cada troca entre elas representa tanto produção quanto distribuição de conhecimentos. Cada troca é valorada em múltiplas moedas, frequentemente sociais, e está situada em um tempo e em um espaço específicos (Hargadon, no prelo).

Para o autor, as características centrais do trabalho baseado em conhecimento nas organizações assemelham-se ao que ocorre no bazar quanto ao intercâmbio de ideias e de expertise

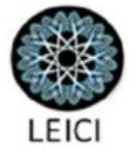


continuamente modelado por forças econômicas e sociais e pelo fluxo contínuo de bens e serviços. Segundo ele, tal perspectiva destaca várias implicações para a gestão do trabalho baseado no conhecimento: (1) o ambiente que envolve o trabalho cria e requer um equilíbrio dinâmico, mais do que estático, na organização; (2) forças de mercado imbricadas parecem efetivas na valoração e na recompensa dada aos empregados pelas contribuições deles para tal equilíbrio; (3) os bens comuns sociais e físicos providos pela organização criam a comunidade necessária aos mercados imbricados.

O bazar pós-moderno é também explorado por Raymond (1999), no livro em que trata do desenvolvimento tecnológico de softwares livres focando o caso do Linux. Ele contrapõe dois modelos de desenvolvimento de softwares: catedral - como ocorre para esse tipo de construção clássica, há um planejamento feito por poucos, emprega-se um modo centralizado e hierarquizado de trabalho para aperfeiçoamentos - e bazar - um modelo amplamente descentralizado, aparentemente caótico, podendo envolver desconhecidos e que aceita muitas ideias e ações de aperfeiçoamento em âmbito mundial, com mediação da internet. Catedral e bazar são modelos com suposições de base opostas.

\subsection{Escopo, Distância e Confiança no Bazar Pós-Moderno}

O modelo de bazar aplicado ao Linux contraria a afirmação de Olson (1971) de que apenas pequenos grupos podem aproveitar os mecanismos sociais necessários para a produção coletiva com sucesso. Segundo diferentes especialistas, o desenvolvimento do sistema operacional Linux, apoiado nas atividades de uma rede on line mundial de muitos colaboradores voluntários pouco ou nada conhecidos, levou a um produto superior em confiabilidade e velocidade a produtos concorrentes concebidos por equipes altamente capacitadas em ricas corporações, como a Microsoft.

Superando as limitações citadas por Olson (1971), a internet permitiu dar alta escala ao número de participantes autônomos de um mesmo projeto numa estrutura de produção par-a-par na qual os participantes não apenas ajudam a desenvolver o produto, mas também o usam. Os participantes são pessoas, organizações e pessoas em organizações que aperfeiçoam e/ou personalizam o Linux, inclusive os produtos derivados dele, como o Android para smart phones e tablets. Além disso, incentivam outros participantes da rede a fazer o mesmo, aproveitando o trabalho uns dos outros e contribuindo um com o outro, mas sem reciprocidade obrigatória. Múltiplos participantes podem, desse modo, também interagir e colaborar presencialmente, como é o caso daqueles de uma mesma organização que desenvolve para si uma versão adaptada do Linux. Entre as motivações para o desenvolvimento voluntário e coletivo do Linux encontram-se o interesse em poder usar gratuitamente um software adaptável e a possibilidade para muitos obterem algum ganho financeiro na distribuição e/ou aperfeiçoamento do software. Também importante é a combinação de uma paixão coletiva por tecnologia, típica de uma cultura geek, com uma frequente ideologia avessa a grandes corporações e/ou às vendas não aderentes à lógica de software livre - uma combinação vista, por exemplo, na criação do sistema operacional GNU (Stallman, 1999). Esses são apenas alguns aspectos socioculturais negligenciados pela perspectiva do mercado neoclássico.

Detalhando-se elementos do escopo e das distâncias no bazar pós-moderno devem-se considerar separadamente as duas concepções: o bazar intraorganizacional de trocas de conhecimento (Hargadon, 2001) e o bazar on line do desenvolvimento de softwares livres (Raymond, 1999). O escopo da primeira, considerando-se também a distância entre os atores, é o das interações internas à organização entre aqueles que trocam conhecimento. Portanto, é o do ambiente interno de uma

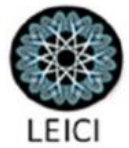


organização, mais restrito do que aquele do bazar tradicional, e ainda mais restrito do que aquele do bazar on line mundial.

As distâncias entre atores transacionais relativas à localização deles no momento das transações relacionam-se logicamente aos respectivos escopos para cada tipo de bazar. O bazar tradicional depende sempre da interação presencial dos atores, normalmente ocorrida pela fala entre eles, o que tende a pô-los numa distância máxima de alguns passos entre si. O bazar intraorganizacional muito comumente tem os atores próximos num mesmo ambiente físico da organização. Contudo, as tecnologias de comunicação atuais têm sido usadas para que pessoas de uma mesma organização troquem conhecimento mesmo a grande distância, de modo sincrônico ou não. Tais tecnologias oferecem, portanto, um campo de interseção entre o bazar intraorganizacional e o bazar on line porque pessoas de uma mesma organização podem se pôr em colaboração on line para desenvolver algum artefato, à imagem do Linux, além de fazê-lo também presencialmente. O bazar on line tende a ter a maior distância física média entre seus atores no momento das transações, dado que estes não estão necessariamente ligados a uma só ou poucas organizações e distribuem-se pelo mundo todo.

Outro padrão possível de distância é o de distância dos locais de origem dos atores, uma característica estabelecida antes do momento das respectivas transações, mas que tende a ter reflexos sobre a ocorrência destas. Parece defensável a ideia de que maiores distâncias tendem a estar relacionadas a modos de vida e de convívio mais distintos, vinculados a padrões socioculturais também mais distintos. Ilustram essa concepção os fluxos de caravanas vindas de longe para o bazar tradicional, sendo a origem dos atores um importante gerador de diversidade sociocultural.

Evidentemente, mesmo que os atores sejam de uma mesma vila ou cidade, outras fontes comuns de diversidade do bazar tradicional com grande impacto nas transações são as diferenças religiosas e de etnia, entre outras, como já destacado por Geertz (1979) sobre Sefrou. Um exemplo de impacto da diversidade sociocultural e da distância de origem sobre as transações pode ser deduzido do estudo de Chakrani (2007): desconhecedores de fórmulas comunicacionais da barganha marroquina, como turistas estrangeiros, têm desvantagem frente aos conhecedores para obter boas negociações.

O bazar on line tende a ter a maior distância média de origem entre os atores no comparativo dos diferentes bazares. Contudo, a internet como canal de comunicação internacional, usando muito frequentemente a língua inglesa e o padrão de código de programação do software livre em questão, tende a ser um filtro modulador dos impactos sobre as transações. Aqueles que não sabem usar o idioma adequado e o código de programação simplesmente não participam de transações. Distância e diversidade sociocultural, por outro lado, podem ser moduladores do tipo de contribuição, do tipo de ator, das ideias e das intenções de cada ator do bazar on line.

No bazar intraorganizacional, excetuando-se as corporações transnacionais, a distância média de origem dos atores em transação tende a ser baixa, como tende a ser moderada a diversidade entre eles. Tal realidade faz com que esse tipo de bazar, quanto à distância de origem e diversidade, tenda a ser o de maior similaridade de condições entre os atores em transação. Por se tratar de um tipo de bazar modelado e delimitado pela estrutura e pelos métodos de trabalho de uma organização, ele apresenta hibridismo com a forma de organização econômica denominada hierarquia por Williamson (1975) e Powell (1990). Nesse sentido, o bazar intraorganizacional tem seus processos e relações regidos em boa parte por uma autoridade central, que é ao menos parcialmente aplicada segundo princípios de racionalidade formal, dada sua busca de eficiência para a maximização de resultados.

A condição de hierarquia torna a formação de parcerias transacionais no bazar intraorganizacional relativamente simples, diferentemente do que se vê no bazar tradicional. 
Membros de uma mesma organização, frequentemente empregados, devem por princípio se conectar e coordenar esforços, são muitas vezes habitués em atividades colaborativas e estão submetidos a um sistema de disciplina e comando promotor da confiança mútua Confiança, no bazar tradicional, é algo raro e, quando existe, é construída com dificuldade devido à restrição proposital de informações nesse contexto e à menor frequência de transações entre habitués.

$\mathrm{O}$ bazar on line tem um modo bem distinto de estabelecimento de confiança. Antes de tudo, o próprio conceito de transação tem particularidades nesse contexto quanto ao fato de que nem sempre alguém que gera uma melhoria de um software aberto faz alguma troca com outra parte em específico. É comum que uma versão aperfeiçoada por um voluntário seja simplesmente deixada à disposição da nuvem de potenciais interessados na internet. Alguém pode obviamente divulgar os benefícios de sua nova versão, inclusive em fóruns on line, mas sem garantia de uso por outra parte.

O mesmo raciocínio se aplica a informações, sugestões e recomendações compartilhadas por participantes da comunidade on line. Assim, todo tipo de contribuição de cada parte (melhoria do código de programação ou não) é disponibilizada para a comunidade on line de interessados. Membros desta podem usá-lo ou não. Suas transações são intermediadas por um repositório on line. Contudo, ocorrem também transações sem essa intermediação, como as transações do bazar intraorganizacional, ou entre entusiastas avulsos em interação direta e às vezes presencial.

Retomando o tema da confiança, a adoção por outras partes tende a ocorrer mais facilmente para pessoas ou organizações que adquirem prestígio na comunidade. Este vem particularmente do reconhecimento de seu talento de programador, de seu engajamento com a causa do software livre e de sua produção de contribuições sólidas para a comunidade. São exemplos emblemáticos disso o precursor do Linux, Linus Torvalds, e o Fedora Linux, um projeto de colaboração mundial entre voluntários lançado em 2003 para ofertar um único repositório confiável softwares. Assim, o prestígio pode ser a base para a confiança necessária à emergência de transações repetitivas, ou seja, as parcerias. Havendo confiança ou não, contudo, todos continuam expostos a certo nível de risco de desonestidade, de erros e de baixa eficiência intencionais ou não. Por isso, a comunidade toma medidas para elevar o nível de confiança e de segurança, mesmo que a natureza codificada e o dinamismo da tecnologia permitam a rápida identificação e o tratamento de ações desonestas, erros e outros problemas. Um exemplo de tais medidas é o Fedora Linux, citado acima, juntando num só repositório diferentes soluções Linux consideradas confiáveis. Algo similar é feito pelo Play Store, do Google, para agrupar aplicativos de celular confiáveis, sem vírus e/ou outros problemas, para o sistema operacional Android, derivado do Linux. Os usuários desse repositório também avaliam cada aplicativo e o comentam, o que ajuda outras pessoas a decidirem sobre o uso de um produto.

\section{Hierarquias e Organizações em Rede}

Como sugerido acima, outro importante contexto transacional do empreendedorismo é a organização - ou hierarquia (Powell, 1990; Williamson, 1975). O empreendedorismo conta então com as capacidades da organização para promover transações, mesmo que internas. Assim, ele é moldado pelas condições organizacionais, inclusive quanto ao estoque de recursos e conexões, assim como aos traços, dinâmicas socioculturais, interesses, habilidades coletivas e outros.

A literatura sobre custo de transação sustenta que uma hierarquia emerge como alternativa ao mercado à medida que atores econômicos buscam fazer, dentro de uma mesma organização, transações e fluxos de recurso que poderiam ocorrer no mercado pela operação de outros atores econômicos. Tendem a ser internalizadas em uma organização as transações necessárias a ela, sobre as quais a direção da organização queira ter controle, que envolvem incerteza sobre seus resultados

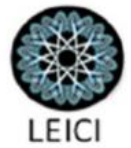


se a cargo de terceiros, são repetitivas e dependem de investimento que terceiros dificilmente fariam. Suprimento e demanda são assim coordenados em uma estrutura naturalmente centralizada.

Características de uma hierarquia, como claras linhas de comando, fronteiras organizacionais, processos formais de tomada de decisão e mecanismos de prestação de conta, são necessários para a produção e o fornecimento a serem constante e atentamente supervisionados numa estrutura centralizada para se manterem velocidade, volume e operações adequados (Powell, 1990). Contudo, a aplicação intensa da racionalidade formal aproxima a hierarquia da condição de máquina, uma organização pouco adaptável, mas que se mantém submetida a condições de imprevisto, mudanças repentinas de mercado e variações de demanda, que exigem flexibilidade (Morgan, 1996).

A flexibilidade é possível na organização em rede (Powell, 1990), um conjunto de dois ou mais atores que mantêm relações de troca duradouras e repetidas e, ao mesmo tempo, não têm uma autoridade organizacional legitimada para arbitrar e resolver eventuais disputas (Podolny e Page, 1998). Quando as relações entre vendedores e compradores são tão recorrentes que se torna difícil de as partes atuarem como entidades completamente separadas, quando um emaranhado de obrigações e reputações faz as partes serem interdependentes, tem-se a organização em rede, na qual não há propriedade ou estrutura legal comum combinada entre as partes (Powell, 1990).

As redes organizacionais são mais leves em seu funcionamento do que uma hierarquia; a alocação de seus recursos ocorre por transações em uma rede de ações recíprocas, preferenciais e mutuamente apoiadoras (Powell, 1990). Benefícios e malefícios são divididos. Na rede, as partes frequentemente abrem mão de defender seus interesses que gerariam prejuízo às demais partes. Isso é impensável no mercado neoliberal, dado o foco das partes na maximização de sua própria eficiência econômica. A racionalidade formal individual acirra a atuação egoísta, a oposição de interesses e a concorrência, particularmente na disputa por clientes, fornecedores e recursos. Na rede, as organizações não vivem por si sós. As expectativas de uma em relação às demais ajustamse de acordo com as circunstâncias e as partes agem continuamente em orientação mútua, usando os conhecimentos mútuos obtidos na comunicação e na solução coletiva de problemas (Powell, 1990).

O conceito de organização em rede exclui características do mercado, como relações eventuais de troca e relações de emprego, assim como os mais básicos arranjos de mercado, como contratos de curto prazo e transações pontuais (Podolny e Page, 1998). Um exemplo de organização em rede são os arranjos de empresas subcontratadas ligadas a uma contratante, como se vê na montagem de aviões e carros. Podolny e Page (1998) dizem que outras várias formas são as joint ventures, alianças estratégicas, grupos empresariais, franquias, consórcio de pesquisa e acordos de terceirização. Contudo, essas formas contam com a arbitragem própria legitimada para eventuais disputas, contrariando a definição de organização em rede desses próprios autores.

Entre os participantes da rede, é comum um espírito de boa vontade, que prioriza a conversa para a solução de problemas ao invés de o comprador simplesmente trocar o vendedor por outro (Dore, 1983), segundo uma relação de confiança e obrigação mútuas (Granovetter, 1995). Dadas essas características, as redes cumprem importantes funções geradoras de benefícios mútuos, como a aprendizagem de habilidades e a aquisição de conhecimentos, ganho de legitimidade, melhoria de desempenho econômico e melhor gestão da dependência de recursos, fora outros benefícios inesperados que são socialmente construídos (Podolny e Page, 1998), como eventuais sentimentos de amizade e companheirismo propícios à colaboração.

\section{Os Diferentes Contextos Transacionais em Relação}

Os contextos que exploramos acima - mercado neoclássico, bazar tradicional, bazar pós- 
moderno, hierarquia e organização em rede - provêm de diferentes origens históricas e disciplinares. Constituem amplas categorias cujas fronteiras conceituais ainda precisam ser firmemente estabelecidas, particularmente devido aos efeitos atuais das tecnologias e da mundialização - internet e aplicativos on line com seus efeitos sobre a distância nas transações, por exemplo. Não obstante, a importância e as interrelações dessas categorias nos parecem autoevidentes. É possível que algumas das experiências de nossos leitores se alinhem apenas com as instituições econômicas do mercado neoclássico. Suspeitamos, no entanto, que a maioria dos leitores, como nós mesmos, estejam cientes de, senão pessoalmente envolvidos com, todas as categorias que descrevemos. Nossa própria experiência, estando em um mundo em emergência, é que a maioria dos acadêmicos e práticos lidam talvez com todos os cinco tipos de contexto transacional semanal ou diariamente e que os elementos deste tendem a se sobrepor, impondo a habilidade para navegá-los ou integrá-los como uma competência importante para muitos de nós.

Como podem então essas categorias ajudar a pensar sobre os reais contextos das ações e do pensamento empreendedores? Seguem alguns tópicos aparentemente promissores para resposta:

1- O empreendedorismo ocorre normalmente nas áreas de transição entre a fronteira do mercado neoclássico e a dos demais contextos transacionais;

2- Áreas não (ou fracamente) institucionalizadas são espaços em que se empreende;

3- Empreende-se frequentemente em contextos transacionais apoiados em instituições fracas;

4- Pode-se falar de bazares imbricados em hierarquias e vice-versa.

\section{Conclusão e Implicações - Retomando a Efetuação e a Bricolagem}

A orientação dos atores em transação nos diferentes tipos de bazar é, de algumas maneiras, próxima do que se vê no caso dos empreendedores efetuadores (Sarasvathy, 2001; 2008). A efetuação é um conceito que surgiu e se desenvolveu, como a bricolagem, à medida que uma variedade de pesquisadores começou a reconhecer e explorar as limitações da racionalidade formal que se presumia ter assumido completo controle sobre a vida moderna. O economista clássico vê o empreendedor como alguém que vasculha o ambiente para encontrar oportunidades sob forma de necessidades de mercado não atendidas, analisa a probabilidade de que um investimento na oportunidade encontrada gerará retorno aceitável e, então, pode investir recursos para explorá-la.

Por outro lado, ao invés de buscar oportunidades no ambiente, o efetuador vasculha sua identidade imediata (quem ele é), suas habilidades e seus contatos e seleciona oportunidades a explorar não pelo retorno calculado corrigido pela percepção de possibilidade de fracasso, mas segundo a proximidade ajustada pela maior perda aceitável. O efetuador pergunta-se "Quem sou eu?", “O que eu sei?", "Quem eu conheço?” e "Qual nível de risco e quais perdas posso aceitar?". Com base nas respostas, identifica ofertas que pode fazer no mercado. Avança então empreendendo com baixo risco e aproveitando criativamente seus meios - identidade, contatos e habilidades.

À medida que esses primeiros avanços com ações empreendedoras aperfeiçoam sua expertise e amplia-se sua rede social, sua clareza quanto à própria identidade e a seu potencial, ele pode expandir o escopo de suas iniciativas tornando-se gradativamente mais agressivo e assegurar melhores taxas de retorno. Aperfeiçoando ainda mais esses atributos, ele se torna mais influente e capaz, passando também a receber mais propostas atraentes de sua rede de relação. O efetuador da perspectiva de Sarasvathy (2001) estaria confortável com a atmosfera personalística e de busca local do bazar tradicional, mas pode ficar muito desconfortável com a omissão de informações e a intensa barganha típica entre atores em transação nesse bazar.

Dada a suposição de base inspirada por Schumpeter $(1934,1939)$ de que a maior parte das 
inovações chegam aos mercados pelas mãos de empreendedores, e dado o grau de comportamento vibrante de busca nos bazares, poder-se-ia esperar encontrar mercados tradicionais ricos em inovação. De fato, qualquer pessoa que tenha algum conhecimento sobre os mercados emergentes acaba por admirar a criatividade bruta e a engenhosidade neles encontradas. Sem contradizer a criatividade nativa dos efetuadores e dos bricolores em economias tradicionais e emergentes, é importante destacar uma diferença central entre estudos recentes sobre bricolagem e efetuação, ou mesmo sobre bootstrapping, do que Geertz (1979) considera ser um dos mais centrais aspectos da cultura de bazar. Na literatura sobre efetuação e bricolagem parece haver a suposição de que os empreendedores mantêm relações colaborativas e abertas com as pessoas com as quais fazem negócio. Contrariamente, Geertz (1979) afirma que os atores das transações do bazar são imensamente preocupados com a omissão de todo tipo de informação sobre oportunidades, recursos, suprimentos, qualidade e preços de outros atores - muitos dos quais são da categoria "quem conheço" (Sarasvathy, 2001). Procedendo assim, eles reduzem o escopo da categoria "o que eu sei” não apenas de outros atores em geral, mas também de seus próprios parceiros em negócios.

Portanto, qualquer adaptação da perspectiva de Sarasvathy (2001) para a economia de bazar teria que se servir de várias questões adicionais quanto a "Quero que quem eu conheço saiba o que estou pensando?" ou "Se eu transacionar com quem eu conheço, ele/ela roubará meu cliente?" - e assim por diante. Nesse sentido, os atores em transação do bazar são muito diferentes dos socializadores espontâneos (Fukayama, 1995), os quais foram socializados para colaborar e compartilhar informações com estranhos sem se cortejarem por muito tempo e sem as intensas negociações que caracterizam transações do bazar. Acreditamos que muito do sucesso tecnológico e de inovação dos países de alta taxa de confiança reside nessa diferença.

Um trabalho mais recente sobre a efetuação e os mercados (Sarasvathy e Dew, 2005) vê o processo de efetuação como majoritariamente voluntário, com potenciais partes das transações não realizando transações ou autoselecionando-se criteriosamente para diminuir perdas possíveis após se implicarem gradativamente em projetos de interesse mútuo. Suspeitamos que, na atmosfera mais politizada do bazar tradicional, envolvendo uma comunidade de longa existência, assim como proteção e articulação da parte de líderes dominadores da comunidade, a liberdade transacional dos efetuadores e sua desenvoltura para começar e fazer crescer um negócio seriam consideravelmente restringidas. Eles poderiam ter que transacionar com influentes partes locais sujeitando-se aos caprichos destes e assim ofendendo sua própria identidade ou poderiam ficar reticentes em compartilhar importantes ideias com parceiros viáveis por receio que estes se apropriem indevidamente de suas ideias inovadoras ou de seus clientes.

O bazar pós-moderno, por outro lado, pareceria muito mais condizente com o modelo de efetuação devido à abertura, natureza voluntária e flexibilidade, assim como em termos de grau de envolvimento e comprometimento. Os efetuadores tendem a ficar pouco confortáveis em uma hierarquia na qual as informações são filtradas para cima e para baixo e a racionalidade burocrática tende a requerer ao menos uma retórica de causação formal. No mercado neoclássico, o tipo ideal de efetuador também estaria um pouco perdido dado que as suposições de base de comunicação instantânea de preço, qualidade e demanda, assim como quanto às oportunidades objetivas exógenas, favorecerão grandes empresas, cujo acesso à larga escala e ao capital para investimento intensivo lhes garante vantagem competitiva.

Por outro lado, pensando-se no bricolor, uma perspectiva histórica ou antropológica nos levaria a esperar que ele sentir-se-ia confortável no bazar tradicional não apenas porque bricolagem e bazares parecem ter suas origens no mesmo período neolítico. De fato, há várias indicações de que assim

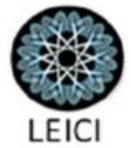


seja. Baker e Nelson (2005), e de modo mais importante Harper (1987), observam que os bricolores priorizam os projetos que eles realizam de acordo com a importância do parceiro de negócio de sua rede social. Portanto, um parceiro de negócio que é um membro central da rede social do bricolor terá suas demandas e problemas atendidos antes de membros mais periféricos. Seu senso de reciprocidade tenderá a ser maior do que o dos efetuadores, que dependem mais do envolvimento voluntário em transações.

A bricolagem envolve fronteiras vagas entre áreas de negócio e campos de expertise, de tal modo que, ao invés de se perguntar "o que eu sei?" como um efetuador, quando se depara com uma demanda ou oportunidade, o bricolor afirmará para si mesmo "não vejo porque não fazer". Em um bazar físico delimitado contendo um número fixo de negociantes altamente habilidosos, em que há apenas estranhos que podem transacionar sem saberem quem pode lhes oferecer os melhores negócios, o bricolor tende a se mostrar hábil para explorar oportunidades que pessoas com um perfil de engenheiro ou de efetuador recusariam. Com seus conhecimentos gerais, ele tende a estar em vantagem comparado aos demais para avaliar a qualidade de fornecedores específicos.

A atitude relaxada do bricolor quanto a regulações e padrões formais não tenderia a impor problemas em um bazar tradicional à medida que ele tenha uma clara ideia de quem são as pessoas influentes em sua comunidade de negócios e consegue ter a habilidade para cair nas graças delas. Ainda assim, como os bricolores tendem a ser relativamente inconformistas e rebeldes, talvez exista um histórico de muitos bricolores banidos ou evitados nos bazares tradicionais devido a sua independência. A atração dos bricolores por catalogar imediatamente os recursos disponíveis e combinar diversos elementos em soluções para interlocutores de negócios tende a ser valiosa em um bazar tradicional. Neste, a habilidade de montar, em um só negócio, um conjunto completo e complexo de soluções para uma caravana de passagem tende a ser valiosíssima porque cada serviço ou bem adicional incorporado a um negócio gera uma comissão ou vantagem adicional para o bricolor. De modo similar, o hábito de o bricolor estocar uma grande variedade de miudezas e outros materiais em sua "tralha" gera a possibilidade de que, em um momento crítico, ele terá algo à mão para resolver um problema urgente de um viajante ou ao menos para contribuir para uma solução viável envolvendo membros de sua rede de relação.

Todos os atributos do bricolor listadas acima apresentam-se como passivos em uma hierarquia ou no mercado neoclássico e carregam grande risco de gerar imagem negativa ou grandes erros no mundo do bazar pós-moderno, principalmente no desenvolvimento de softwares livres, tão dependente de precisão e atenção aos detalhes de regras de produção. Falta de especialização, intolerância a regras, independência e grande estoque de objetos de segunda mão e fora de padrão são sacrilégio para hierarquias e são contra-competitivos em mercados de massa impessoais e padronizados. No bazar pós-moderno, especificamente na troca de conhecimentos do bazar intraorganizacional, mesmo podendo ser fonte de problemas, como comportamento subversivo e soluções de baixa qualidade, esses itens podem ajudar a "pensar fora da caixa" e a gerar soluções criativas, à imagem do papel dos intraempreendedores (Pinchot, 1985). Algo semelhante pode ser pensado até mesmo para as hierarquias, nas quais um bricolor poderia injetar alguma desordem criativa. No bazar online, os itens são talvez um pouco mais úteis, mas ainda de utilidade limitada devido à ampla dimensão da rede de negócios com laços muito fracos, assim como à presença de claros líderes tecnológicos ou pessoas que se deva consultar após localizá-los com buscas online.

Como chegamos a mencionar acima, contudo, um real desafio da nova economia parece ser o de ter a habilidade de se fazer a mediação entre um ou mais tipos de contexto transacional da ação empreendedora: bazares tradicionais vendendo produtos de mercados em massa, produtos feitos nos

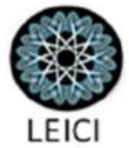


bazares pós-modernos, mas vendidos e aplicados em hierarquias governamentais, organizações em rede conjugadas com bazares pós-modernos ou, talvez ainda mais comumente, uma mescla de todos os cinco tipos de contexto. Para apresentar a adaptabilidade necessária à superação do desafio, suspeitamos que o efetuador possa ser o mais privilegiado, dado seu modo gradual, atento aos riscos e integrador de colaboradores. Pontos fortes como esses podem ajudar a entender o tremendo desenvolvimento do interesse de pessoas da prática e da academia pelo tema lançado por Sarasvathy (2001).

\section{ANEXO}

Quadro 1- Comparação entre ambientes transacionais (ampliação do comparativo de Powell, 1990)

\begin{tabular}{|c|c|c|c|c|c|}
\hline \multirow{3}{*}{ Características-chave } & \multicolumn{5}{|c|}{ FORMAS } \\
\hline & \multicolumn{3}{|c|}{ Segundo Powell (1990) } & \multicolumn{2}{|c|}{ A partir de nosso próprio trabalho } \\
\hline & Mercado & Hierarquia & Organização em rede & Bazar & $\begin{array}{l}\text { Bazar pós-moderno } \\
\text { (bazar como metáfora) }\end{array}$ \\
\hline Base normativa & $\begin{array}{l}\text { Contrato-direitos } \\
\text { de propriedade }\end{array}$ & Relação de emprego & Forças complementares & $\begin{array}{l}\text { Normas, hábito e } \\
\text { cultura locais }\end{array}$ & $\begin{array}{l}\text { Cultura do estilo de } \\
\text { vida e/ou da profissão }\end{array}$ \\
\hline Meios de comunicação & Preços & Rotinas & $\begin{array}{l}\text { Relacionais repetitivos, } \\
\text { contado com múltiplas transações no } \\
\text { longo prazo entre as mesmas partes }\end{array}$ & $\begin{array}{l}\text { Relacionais episódicos, } \\
\text { para cada transação pontual } \\
\text { entre desconhecidos, e } \\
\text { relacionais repetitivos, } \\
\text { para habitués }\end{array}$ & $\begin{array}{l}\text { Relacionais repetitivos } \\
\text { ou ocasionais, mediados } \\
\text { ou não pela internet - } \\
\text { dependendo se se trata ou não } \\
\text { de interações } \\
\text { intraorganizacionais }\end{array}$ \\
\hline $\begin{array}{l}\text { Métodos de resolução } \\
\text { de conflitos }\end{array}$ & $\begin{array}{l}\text { Discussão de preços } \\
\text { - recurso à justiça }\end{array}$ & $\begin{array}{l}\text { Deliberação } \\
\text { administrativa - } \\
\text { supervisão }\end{array}$ & $\begin{array}{l}\text { Norma de reciprocidade - } \\
\text { preocupação com a } \\
\text { reputação }\end{array}$ & $\begin{array}{l}\text { Conformar-se, no caso de } \\
\text { transações pontuais, e } \\
\text { desconexão, para os } \\
\text { habitués }\end{array}$ & $\begin{array}{l}\text { Interferência de um } \\
\text { mediador e/ou } \\
\text { desconexão entre as } \\
\text { partes }\end{array}$ \\
\hline Grau de flexibilidade & Alto & Baixo & Médio & $\begin{array}{l}\text { Médio, apesar da abundância } \\
\text { de partes transacionais } \\
\text { possíveis, devido à restrição de } \\
\text { informações para se trocar } \\
\text { vendedores }\end{array}$ & $\begin{array}{l}\text { Médio em ambiente } \\
\text { intraorganizacional e alto na } \\
\text { internet }\end{array}$ \\
\hline $\begin{array}{l}\text { Nível de engajamento } \\
\text { entre as partes }\end{array}$ & Baixo & Médio a alto & Médio a alto & $\begin{array}{l}\text { Médio para habitués e } \\
\text { baixo para desconhecidos }\end{array}$ & $\begin{array}{l}\text { Alto em ambiente } \\
\text { intraorganizacional e baixo } \\
\text { na internet, com exceção dos } \\
\text { habitués }\end{array}$ \\
\hline Tom ou clima & $\begin{array}{l}\text { Precisão e/ou } \\
\text { desconfiança }\end{array}$ & Formal, burocrático & Aberto, benefícios mútuos & $\begin{array}{l}\text { Desconfiança, } \\
\text { insegurança e/ou prazer } \\
\text { lúdico com a arte da } \\
\text { barganha }\end{array}$ & $\begin{array}{l}\text { Cumprimento do } \\
\text { dever em ambiente } \\
\text { intraorganizacional e } \\
\text { entretenimento na } \\
\text { internet }\end{array}$ \\
\hline $\begin{array}{l}\text { Preferências ou escolha } \\
\text { do ator }\end{array}$ & Independente & Dependente & Interdependente & Conveniência & $\begin{array}{l}\text { Não independente em } \\
\text { ambiente intraorganizacional } \\
\text { e independente/por } \\
\text { afinidade na internet }\end{array}$ \\
\hline \multirow[t]{3}{*}{ Mesclagem de formas } & $\begin{array}{l}\text { Repetição de } \\
\text { transações (Geertz, } \\
1978)\end{array}$ & $\begin{array}{l}\text { Organização informal } \\
\text { (Dalton, 1957) }\end{array}$ & Hierarquia de status & $\begin{array}{l}\text { Repetição de transações } \\
\text { para os habitués }\end{array}$ & $\begin{array}{l}\text { Laços sociais e } \\
\text { repetição fazem } \\
\text { aproximação com } \\
\text { organização em rede }\end{array}$ \\
\hline & \multirow{2}{*}{$\begin{array}{l}\text { Contratos como } \\
\text { documentos } \\
\text { hierárquicos } \\
\text { (Stinchcombe, 1985) }\end{array}$} & \multirow{2}{*}{$\begin{array}{l}\text { Traços similares aos } \\
\text { de mercado: centros } \\
\text { de lucro, transferência } \\
\text { de preços (Eccles, 1985) }\end{array}$} & Parceiros múltiplos & \multirow{2}{*}{$\begin{array}{l}\text { Semelhança com } \\
\text { mercado para desconhecidos }\end{array}$} & \multirow{2}{*}{$\begin{array}{l}\text { Regras formais em } \\
\text { ambiente intraorganizacional }\end{array}$} \\
\hline & & & Regras formais & & \\
\hline $\begin{array}{l}\text { Nível de análise na } \\
\text { pesquisa (não considerado } \\
\text { por Powell, 1990) }\end{array}$ & Organizacional & Individual & Organizacional & Individual & Individual \\
\hline
\end{tabular}

\section{REFERÊNCIAS}

Archer, G. R., Baker, T., Mauer, R. (2009). Towards an alternative theory of entrepreneurial success: integrating bricolage, effectuation and improvisation. Frontiers of Entrepreneurship Research, 29 (6). Recuperado de http://digitalknowledge.babson.edu/fer/vol29/iss6/4 em 5 de fevereiro de 2018. 
Baker, T., Nelson, R. E. (2005). Creating something from nothing: resource construction through entrepreneurial bricolage. Administrative Science Quarterly, 50(3), 329-366.

Cefaï, D. (2003). Le souk de Sefrou: analyse culturelle d'une forme sociale. In Geertz, C. Le souk de Sefrou. Paris : Bouchene, p. 7-53.

Chakrani, B. (2007). Cultural context and speech act theory: a socio-pragmatic analysis of bargaining exchanges in Morocco. Anais do Fifteenth Annual Symposium About Language and Society-Austin. Recuperado de http://citeseerx.ist.psu.edu/viewdoc/download?doi=10.1.1.585.8049\&rep=rep1\&type=pdf - em 5 de fevereito de 2018.

Cournot, A. A. (1838). Recherches sur les principes mathématiques de la théorie des richesses. Hachette.

Davidson, P. (2008). The entrepreneurship research challenge. Massachusetts: Edward Elgar.

Dore, R. (1983). Goodwill and the spirit of market capitalism. The British Journal of Sociology, 34(4), 459-482.

Durkheim, É. (1977). Da divisão do trabalho social. São Paulo: Martins Fontes.

Fukuyama, F. (1995). Trust: The social virtues and the creation of prosperity. Free Press Paperbacks.

Geertz, C. (1978). The bazaar economy: information and search in peasant marketing. The American Economic Review, 68(2), 28-32.

Geertz, C. (1979). Suq: the bazaar economy in Sefrou. In C. Geertz, H. Geertz and L. Rosen (Eds.). Meaning and order in Moroccan society. Cambridge: Cambridge University Press, p. 123-225.

Granovetter, M. (1985). Economic action and social structure: the problem of embeddedness. American Journal of Sociology, 91(3): 481-510.

Granovetter, M. (1995). Coase revisited: Business groups in the modern economy. Industrial and Corporate Change, 4(1), 93-130.

Hargadon, A. B. (2001). The knowledge bazaar. Anais do Academy of Management Meeting (Vol. 2001, No. 1, pp. A1-A6). Academy of Management.

Hargadon, A. B. (en presse). The firm as knowledge bazaar.

Harper, D. (1987). Working knowledge: skill and community in a small shop. Chicago: University of Chicago Press.

Lalèyê, I.-P., Panhuys, H., Verhelst, T., Zaoual, H. (eds.) (1996). Organisations économiques et cultures africaines : de l'homo oeconomicus à l'homo situs. Paris : Éditions L'Harmattan.

Lévi-Strauss, C. (1962). La pensée sauvage. Paris: Plon.

Lima, E., Nelson, R. E. (2016). Après le déluge : l'entrepreneuriat social servi par l'effectuation, sa version contraire ou étendue, et le bricolage. Anais do CIFEPME. Trois-Rivières.

McMillan, J. (2003). Reinventing the bazaar: a natural history of markets. WW Norton \& Company.

Mello, P. P. T. (2005). Mercadores de significados: o bazar como porta de entrada ao universo marroquino. Laboratório de Etnografia Metropolitana - UFRJ. Recuperado de http://www.lemetro.ifcs.ufrj.br/suq_de_sefrou_definitivo.pdf em 5 de fevereiro de 2018. Morgan, G. (1996). Imagens da organização. São Paulo: Atlas. 
Moreau, R. (2004). L'identité entrepreneuriale de soi: Le cas de 45 fondateurs d'entreprise de nouvelle technologie. Revue Internationale PME, 17(2), 11-42.

Olson, M. (1971). The logic of collective action: Public goods and the theory of groups. Harvard Economic Studies.

Pinchot, G. (1985). Intrapreneurship. Harper and Row Publishers.

Podolny, J. M., Page, K. L. (1998). Network forms of organization. Annual Review of Sociology, 24(1), 57-76.

Powell, W. W. (1990). Neither market nor hierarchy: network forms of organization. Research in Organizational Behavior, 12: 295-336.

Raymond, E. S. (2001). The cathedral and the bazaar: musings on Linux and open source by an accidental revolutionary. San Francisco: O'Reilly and Associates.

Ruef, M., Lounsbury, M. (2007). Introduction: the sociology of entrepreneurship. In M. Ruef, M. Lounsbury (eds.). The sociology of entrepreneurship (pp. 1-32). Vol. 25, JAI Press.

Sarasvathy, S. (2001). Causation and effectuation: toward a theoretical shift from economic inevitability to entrepreneurial contingency. Academy of Management Review, 26, 243-263.

Sarasvathy, S. D. (2008). Effectuation: elements of entrepreneurial expertise. Cheltenham: Edward Elgar Publishing.

Sarasvathy, S., Dew, N. (2005). New market creation through transformation. Journal of Evolutionary Economics, 15(5), 533-565.

Schumpeter, J. A. (1934, 1980). The theory of economic development. London: Oxford University Press.

Schumpeter, J. A. (1939, 1982). Business cycles. Philadelphia: Porcupine Press.

Stallman, R. (1999). The GNU operating system and the free software movement. In C. DiBona, S. Ockman, M. Stone (eds.). Open sources: voices from the open source revolution. Sebastopol, CA: O'Reilly, p. 53-70.

Watson, T. J. (2013). Entrepreneurship in action: bringing together the individual, organizational and institutional dimensions of entrepreneurial action. Entrepreneurship \& Regional Development, 25(5-6), 404-422.

Weber, M. (1968). História geral da economia. São Paulo: Mestre Jou.

Weber, M. (1947). The Theory of Social and Economic Organization. New York: Free Press.

Weber, M. (1991). Economia e sociedade. Brasília: Editora da UnB.

Welter, F. (2011). Contextualizing entrepreneurship - conceptual challenges and ways forward. Entrepreneurship Theory and Practice, 35(1), 165-184.

Welter, F., Gartner, W. B. (2016). A research agenda for entrepreneurship and context. Cheltenham: Edward Elgar.

Williamson, O. E. (1975). Markets and hierarchies: analysis and antitrust implications. New York: Free Press. 